\title{
Methylnaltrexone Potentiates the Anti-Angiogenic Effects of mTOR Inhibitors
}

\author{
Journal of Angiogenesis Research 2:5 I DOI: 10.1186/2040-2384-2-5 I C Li et al.; licensee Publiverse Online S.R.L. \\ 2010 \\ Received: 7 Jun 2009 | Accepted: 19 Jun 2010 | Published: 19 Jun 2010 \\ Singleton Patrick A ${ }^{@}$, Mambetsariev Nurbek, Lennon Frances E, Mathew Biji, Siegler Jessica H, \\ Moreno-Vinasco Liliana, Salgia Ravi, Moss Jonathan, Garcia Joe GN \\ ${ }^{+}$Contributed equally ${ }^{@}$ Corresponding author
}

\begin{abstract}
Background

Recent cancer therapies include drugs that target both tumor growth and angiogenesis including mammalian target of rapamycin (mTOR) inhibitors. Since mTOR inhibitor therapy is associated with significant side effects, we examined potential agents that can reduce the therapeutic dose.
\end{abstract}

\section{Methods}

Methylnaltrexone (MNTX), a peripheral mu opioid receptor (MOR) antagonist, in combination with the mTOR inhibitors temsirolimus and/or rapamycin, was evaluated for inhibition of VEGF-induced human pulmonary microvascular endothelial cell (EC) proliferation and migration as well as in vivo angiogenesis (mouse Matrigel plug assay).

\section{Results}

MNTX inhibited VEGF-induced EC proliferation and migration with an IC50 of $\sim 100 \mathrm{nM}$. Adding $10 \mathrm{nM}$ MNTX to EC shifted the IC50 of temsirolimus inhibition of VEGF-induced proliferation and migration from $\sim 10 \mathrm{nM}$ to $\sim 1 \mathrm{nM}$ and from $\sim 50$ to $\sim 10 \mathrm{nM}$ respectively. We observed similar effects with rapamycin. On a mechanistic level, we observed that MNTX increased EC plasma membrane-associated tyrosine phosphate activity. Inhibition of tyrosine phosphatase activity $(3,4-$ dephostatin) blocked the synergy between MNTX and temsirolimus and increased VEGF-induced tyrosine phosphorylation of Src with enhanced PI3 kinase and mTOR Complex 2-dependent phosphorylation of Akt and subsequent activation of mTOR Complex 1 (rapamycin and temsirolimus target), while silencing Src, Akt or mTOR complex 2 components blocked VEGF-induced angiogenic events.

\section{Conclusions}

Our data indicate that MNTX exerts a synergistic effect with rapamycin and temsirolimus on inhibition of VEGF-induced human EC proliferation and migration and in vivo angiogenesis. Therefore, addition of MNTX could potentially lower the dose of mTOR inhibitors which could improve therapeutic index.

\section{Background}

Recent therapeutic interventions for the inhibition of cancer progression include drugs that target both tumor growth and angiogenesis. Mammalian target of rapamycin (mTOR) inhibitors, including sirolimus (rapamycin) and temsirolimus, are potential therapeutic agents for hepatocellular cancer and renal cell carcinoma due to their anti-proliferative and antiangiogenic properties. However, these mTOR inhibitors are often associated with unwanted side effects including rash, asthenia, mucositis, nausea, edema, anemia, hyperglycemia, thrombocytopenia, hyperlipaenia and anorexia [ 1-5]. Therefore, agents that can reduce the therapeutic concentration of these drugs could have significant clinical utility. We recently demonstrated that mu opioid agonists stimulate VEGF-induced angiogenesis via receptor transactivation and that mu opioid antagonists can inhibit VEGF receptor signaling [ 6]. During the course of these investigations, we also noted an effect of the peripheral opiate antagonist methylnaltrexone (MNTX) on endothelial cell migration and proliferation that occurred beyond the VEGF receptor, through a mechanism that involves inhibition of Src and Akt. We therefore hypothesized that methylnaltrexone could have synergistic effects with anti-angiogenic drugs (i.e. mTOR inhibitors).

In this study, we demonstrate that methylnaltrexone (MNTX) acts synergistically with the mTOR inhibitors, rapamycin and temsirolimus, on inhibition of VEGF-induced angiogenic events. Specifically, MNTX inhibited EC proliferation with an IC50 of $\sim 100 \mathrm{nM}$. Adding $10 \mathrm{nM}$ MNTX shifted the IC50 of temsirolimus on EC proliferation from $\sim 10 \mathrm{nM}$ to $\sim 1 \mathrm{nM}$. Further, 
adding $10 \mathrm{nM}$ MNTX shifted the IC50 of temsirolimus on inhibition of EC migration from $\sim 50 \mathrm{nM}$ to $\sim 10 \mathrm{nM}$. The synergistic effects of MNTX and temsirolimus were also demonstrated in an in vivo model of angiogenesis (mouse Matrigel plug assay). There was a shift in the IC50 on inhibition of VEGF-induced EC proliferation and migration with MNTX and rapamycin. The synergistic mechanism involves MNTX activation of tyrosine phosphatase activity with consequent inhibition of VEGF-induced Src activation. MNTX-induced Src inactivation results in inhibition of PI3 kinase and mTOR signaling required for Akt activation (serine/threonine phosphorylation). These results suggest addition of MNTX could potentially lower the therapeutic doses of mTOR inhibitors including rapamycin and temsirolimus.

\section{Methods}

\section{Cell Culture and Reagents}

Human pulmonary microvascular EC (HPMVEC) were obtained from Cambrex (Walkersville, MD) and cultured as previously described $[7,8]$ in EBM-2 complete medium (Cambrex) at $37^{\circ} \mathrm{C}$ in a humidified atmosphere of $5 \% \mathrm{CO}{ }_{2}, 95 \%$ air, with passages 6-10 used for experimentation. Unless otherwise specified, reagents were obtained from Sigma (St. Louis, MO). Vascular endothelial growth factor (VEGF) was purchased from R\&D Systems (Minneapolis, MN). Methylnaltrexone bromide or methylnaltrexone (MNTX) was purchased from Mallinckrodt Specialty Chemicals (Phillipsburg, NJ). Temsirolimus was acquired through Wyeth Pharmaceuticals. Rapamycin was purchased from Sigma (St. Louis, MO). Reagents for SDS-PAGE electrophoresis were purchased from Bio-Rad (Richmond, CA) and Immobilon-P transfer membrane was purchased from Millipore (Millipore Corp., Bedford, MA). Rabbit anti-pSer ${ }^{473}$ Akt, rabbit anti-pThr ${ }^{308}$ Akt, rabbit anti-Akt, rabbit anti-pThr ${ }^{389}$ p70 S6K and anti-p70 S6K antibodies were purchased from Cell Signaling Technologies (Danvers, MA). Rabbit anti-mTOR, rabbit anti-Rictor and rabbit anti-FKBP12 antibodies were purchased from Santa Cruz Biotechnology (Santa Cruz, CA). Mouse anti-pp60src antibody was purchased from Upstate Biotechnologies (Lake Placid, NY). LY294002 was purchased from EMD Biosciences (Gibbstown, NJ). Mouse anti- $\beta$-actin antibody, rabbit anti-phosphotyrosine ${ }^{418}$ Src antibody and naltrexone, were purchased from Sigma (St. Louis, MO). Secondary horseradish peroxidase (HRP)-labeled antibodies were purchased from Amersham Biosciences (Piscataway, NJ).

\section{Immunoprecipitation and Immunoblotting}

Cellular materials from treated or untreated HPMVEC were incubated with IP buffer (50 mM HEPES (pH 7.5), $150 \mathrm{mM}$ $\mathrm{NaCl}, 20 \mathrm{mM} \mathrm{MgCl}_{2}, 1 \%$ Nonidet P-40 (NP-40), $0.4 \mathrm{mM} \mathrm{Na}_{3} \mathrm{VO}_{4}, 40 \mathrm{mM} \mathrm{NaF}, 50 \mu \mathrm{M}$ okadaic acid, $0.2 \mathrm{mM}$ phenylmethylsulfonyl fluoride, 1:250 dilution of Calbiochem protease inhibitor mixture 3). The samples were then immunoprecipitated with either anti-Raptor or anti-Rictor IgG followed by SDS-PAGE in 4-15\% polyacrylamide gels, transfer onto Immobilon ${ }^{\mathrm{TM}}$ membranes, and developed with specific primary and second ary antibodies. Visualization of immunoreactive bands was achieved using enhanced chemiluminescence (Amersham Biosciences).

\section{Transfection of siRNA against mTOR, Src, Rictor, FKBP12 and Akt}

The siRNA for human mTOR, Src, Rictor, FKBP12 and Akt were purchased from Santa Cruz Biotechnology (Santa Cruz, $\mathrm{CA}$ ) and were utilized according to the manufacturer's specifications. Briefly, human lung EC were transfected with siRNA using siPORTamine ${ }^{\mathrm{TM}}$ as the transfection reagent (Ambion, TX). Cells ( 40\% confluent) were serum-starved for 1 hour followed by incubated with $250 \mathrm{nM}$ of target siRNA (or scramble siRNA or no siRNA) for 6 hours in serum-free media. The serum-containing media was then added (1\% serum final concentration) for $42 \mathrm{~h}$ before biochemical experiments and/or functional assays were conducted.

\section{Human Pulmonary Microvascular EC Migration Assay}

Twenty-four transwell units with $8 \mu \mathrm{M}$ pore size were used for monitoring in vitro cell migration. HPMVEC $(\sim 1 \times 10$ ${ }^{4}$ cells/well) were plated with various treatments (MNTX, temsirolimus, LY294002, 3,4-Dephostatin or siRNA) to the upper chamber and VEGF (100 nM) was added to the lower chamber. Cells were allowed to migrate for 18 hours. Cells from the upper and lower chamber were quantitated using the CellTiter96 ${ }^{\mathrm{TM}}$ MTS assay (Promega, San Luis Obispo, CA) and read at $492 \mathrm{~nm} . \%$ migration was defined as the \# of cells in the lower chamber \% the number of cells in both the upper and lower chamber. Each assay was set up in triplicate, repeated at least five times and analyzed statistically by Student's $t$ test (with statistical significance set at $P<0.05)$.

\section{Human Pulmonary Microvascular EC Proliferation Assay}

For measuring cell growth, HPMVEC $\left[5 \times 10^{3}\right.$ cells/well pretreated with various agents (MNTX, temsirolimus, LY294002, $3,4-$-Dephostatin or siRNA) were incubated with $0.2 \mathrm{ml}$ of serum-free media containing $100 \mathrm{nM} \mathrm{VEGF}$ for $24 \mathrm{~h}$ at $37^{\circ} \mathrm{C}$ in $5 \% \mathrm{CO}_{2} / 95 \%$ air in 96 -well culture plates. The in vitro cell proliferation assay was analyzed by measuring increases in cell number using the CellTiter96 ${ }^{\mathrm{TM}}$ MTS assay (Promega, San Luis Obispo, CA) and read at $492 \mathrm{~nm}$. Each assay was set up in triplicate, repeated at least five times and analyzed statistically by Student's $t$ test (with statistical significance set at $P<0.05$ ).

\section{Tyrosine Phosphatase Assay}

HLMVEC were treated with MNTX (100 nM), VEGF (100 nM) and/or morphine (100 nM) for 5 minutes. Lysates were then obtained and further purified to enrich plasma membrane-associated proteins by wheat germ agglutinin (WGA) affinity as previously described [9] and analyzed for tyrosine phosphatase activity using the fluorometric Rediplate ${ }^{\mathrm{TM}} 96 \mathrm{EnzChek}$ Tyrosine Phosphatase Assay Kit (Invitrogen (Molecular Probes), Eugene, OR) as we have previously described [ 10]. Briefly, cellular materials are incubated in reaction buffer at $30^{\circ} \mathrm{C}$ and then added to a 96 well plate coated with 6,8 -difluoro-4- 
methylumbelliferyl phosphate (DiFMUP). Tyrosine phosphatase activity cleaves DiFMUP into DiFMU with an excitation/emission maxima of 358/452 nm.

\section{In Vivo Angiogenesis Assay}

The Matrigel plug assay was used to assess in vivo angiogenesis [ 11]. 10-week-old female C57BL/6 mice (Jackson Laboratory, Bar Harbor, ME) were injected subcutaneously on the ventral abdomen with $500 \mu$ l Matrigel (BD Biosciences, San Jose, CA) containing either MNTX $(100 \mathrm{nM})$, temsirolimus $(10 \mathrm{nM})$, or both drugs (100 nM MNTX and $10 \mathrm{nM}$ temsirolimus). $20 \mathrm{ng}$ VEGF was added to all Matrigel plugs. After 21 days, the plugs were removed and analyzed for hemoglobin content. The plugs were weighed and homogenized, and their hemoglobin content was quantified using the QuantiChrom $^{\mathrm{TM}}$ hemoglobin assay kit (BioAssay Systems, Hayward, CA).

\section{Results}

\section{Analysis of methylnaltrexone (MNTX) synergy with mTOR inhibitors on inhibition of human endothelial cell (EC) proliferation and migration}

Given our previous published data indicating that MNTX inhibits VEGF-induced Akt activation [ 10], we hypothesized that MNTX could have synergistic effects with anti-angiogenic drugs that regulate Akt signaling including mTOR inhibitors.

Figure 1-A indicates that MNTX inhibits EC proliferation with an IC50 of $\sim 100 \mathrm{nM}$. Adding ten fold lower concentration of MNTX $(10 \mathrm{nM})$ to human EC shifted the IC50 of temsirolimus from $\sim 10 \mathrm{nM}$ to $\sim 1 \mathrm{nM}$. These results were further confirmed with isobologram analysis [ 12] (Figure 1-B). Adding $10 \mathrm{nM}$ MNTX shifted the IC50 of temsirolimus on inhibition of EC migration from $\sim 50 \mathrm{nM}$ to $\sim 10 \mathrm{nM}$ (Figure 1-C) and the synergy was confirmed using isobologram analysis [ 12] (Figure 1D). These synergistic effects were not observed with the uncharged mu opioid antagonist, naltrexone (Figure 2-A, B ; Figure 3-A, B ). The synergistic effects of MNTX were paralleled with the mTOR inhibitor, rapamycin (see Additional Figure 1).

Figure 1

\section{A.}

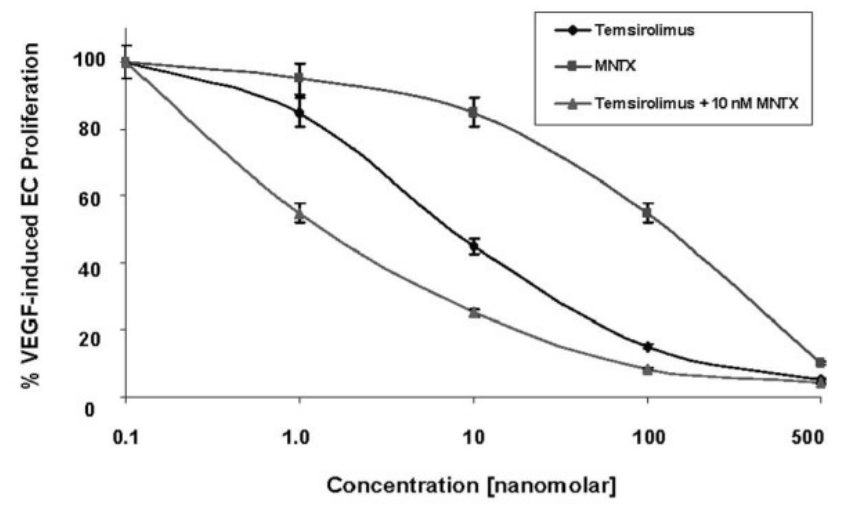

C.

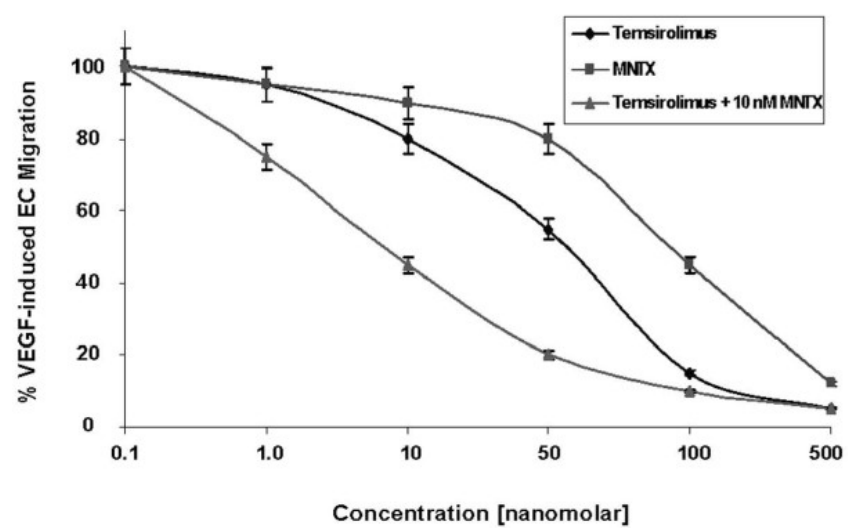

B.

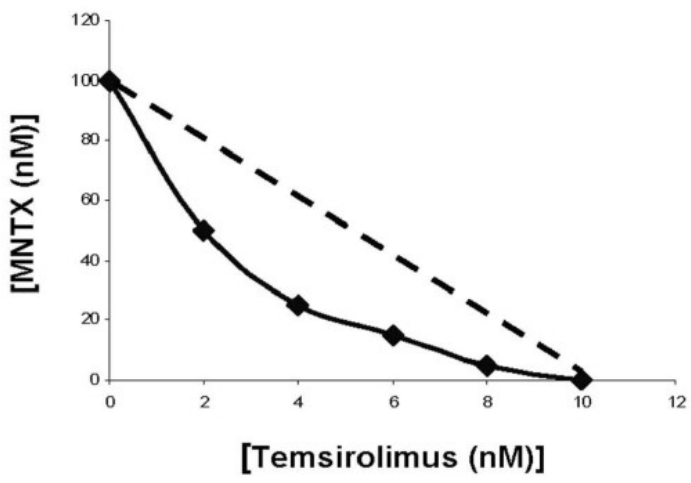

D.

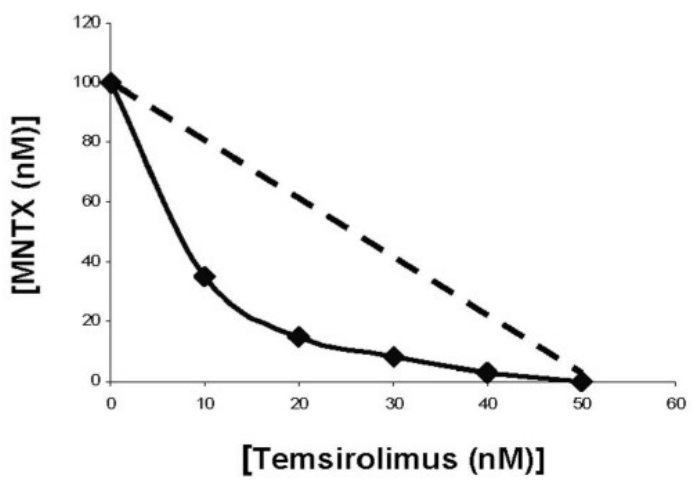


Determination of methylnaltrexone (MNTX) synergistic effects with temsirolimus on inhibition of VEGF-induced human endothelial cell (EC) proliferation and migration. Panel A: Graphical representation of human EC assayed for VEGF (100 $\mathrm{nM}$ )-induced proliferation (24 hours) in the presence or absence of $0.1,1.0,10,100$ or $500 \mathrm{nM} \mathrm{MNTX}$, temsirolimus, or temsirolimus + $10 \mathrm{nM}$ MNTX. Experiments were performed in triplicate. Error bars = standard deviation. Panel B: Isobologram analysis of the combination of MNTX and temsirolimus on inhibition of VEGF-induced proliferation. The dashed line indicates a zero interaction for the isobole. The shift to the left indicates a synergistic interaction. Panel C: Graphical representation of human EC assayed for VEGF (100 nM)-induced migration (24 hours) in the presence or absence of $0.1,1.0,10,100$ or $500 \mathrm{nM}$ MNTX, temsirolimus, or temsirolimus $+10 \mathrm{nM}$ MNTX. Experiments were performed in triplicate. Error bars = standard deviation. Panel D: Isobologram analysis of the combination of MNTX and temsirolimus on inhibition of VEGF-induced migration. The dashed line indicates a zero interaction for the isobole. The shift to the left indicates a synergistic interaction.

Figure 2
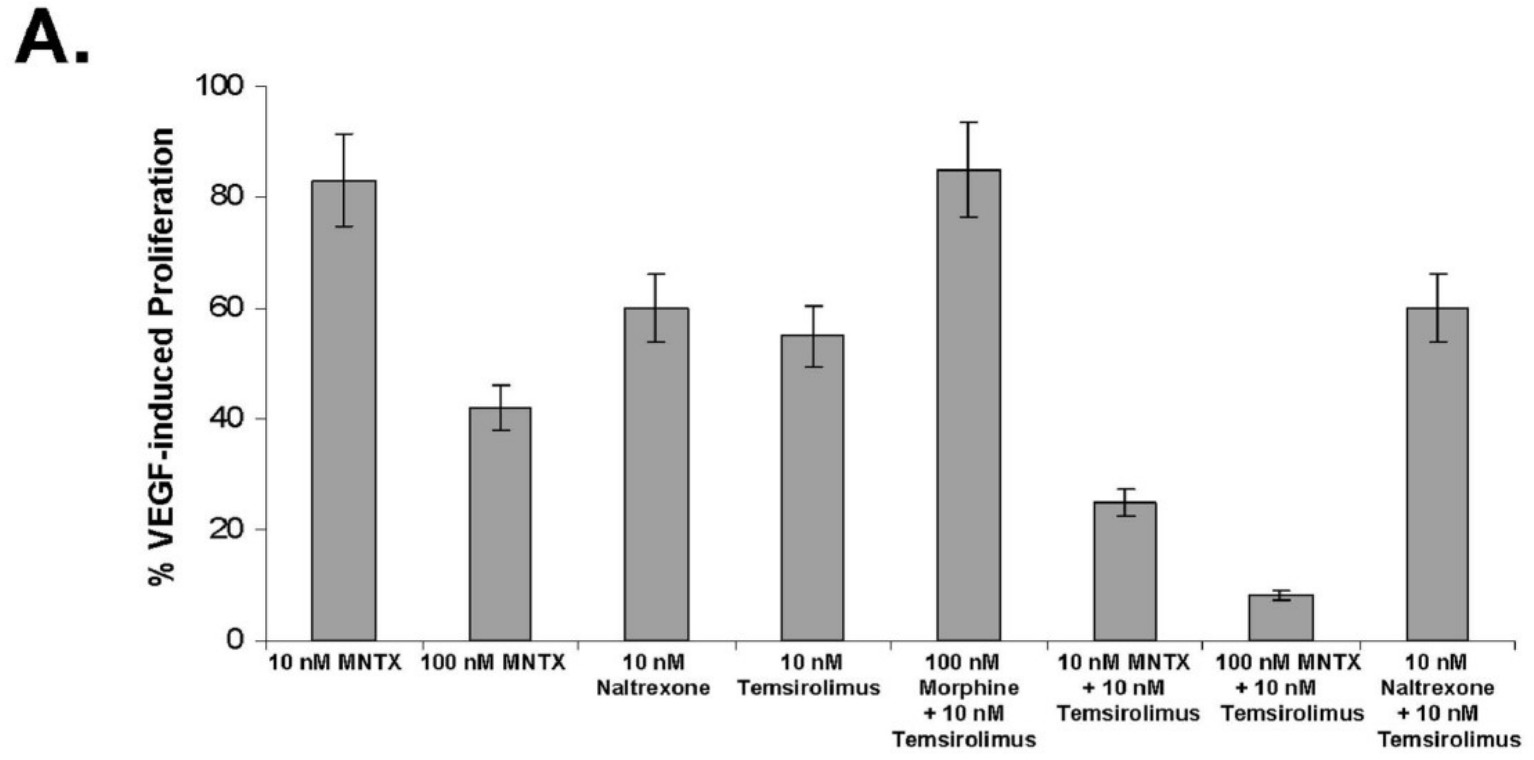

B.

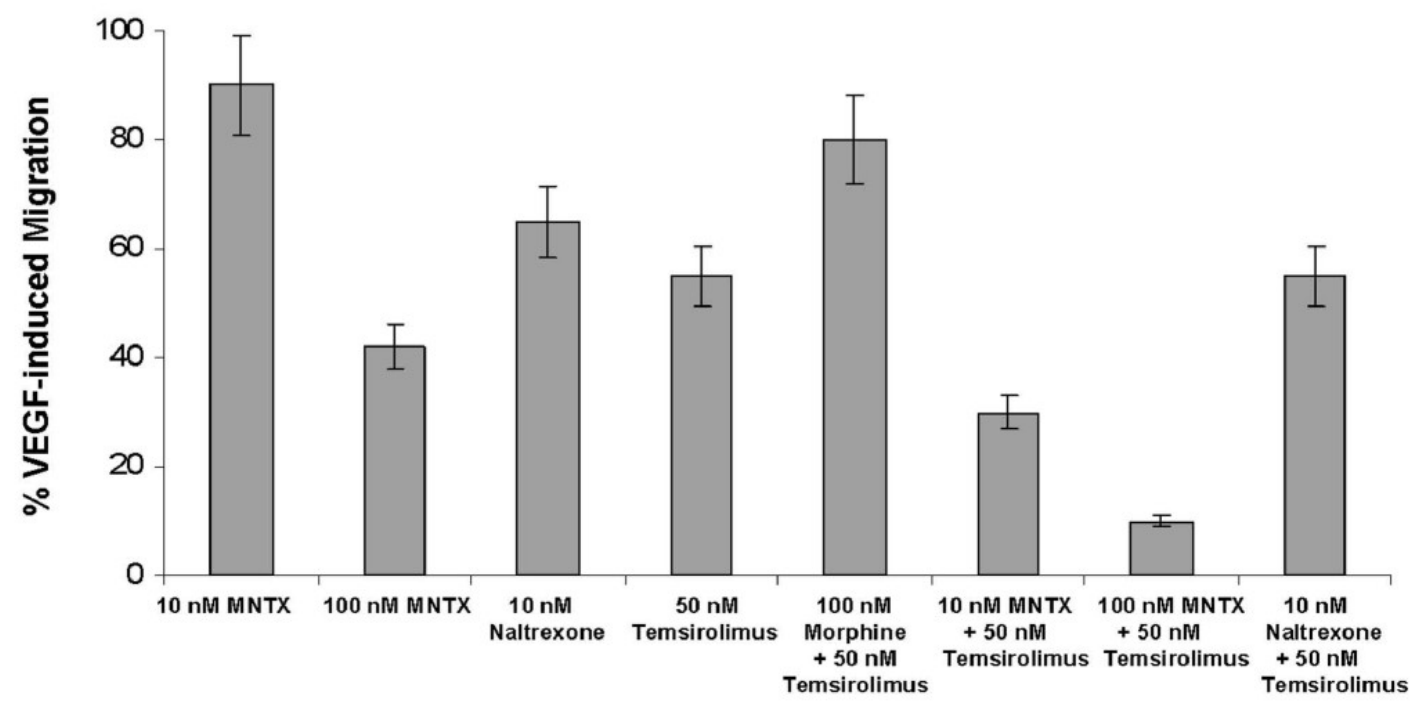

Comparison of MNTX and naltrexone on synergy with temsirolimus on VEGF-induced angiogenic events. Panel A: Bar graph representation of human EC assayed for VEGF (100 nM)-induced proliferation ( 24 hours) in the presence or absence of $10 \mathrm{nM}$ MNTX, $100 \mathrm{nM}$ MNTX, $10 \mathrm{nM}$ naltrexone, $10 \mathrm{nM}$ temsirolimus, $100 \mathrm{nM}$ morphine $+10 \mathrm{nM}$ temsirolimus, $10 \mathrm{nM}$ MNTX $+10 \mathrm{nM}$ temsirolimus, $100 \mathrm{nM}$ MNTX $+10 \mathrm{nM}$ temsirolimus or $10 \mathrm{nM}$ naloxone $+10 \mathrm{nM}$ temsirolimus. Experiments were performed in triplicate. Error bars = standard deviation. Panel B: Bar graph representation of human EC assayed for VEGF (100 nM)-induced migration (24 hours) in the presence or absence of 10 nM MNTX, $100 \mathrm{nM}$ MNTX, $10 \mathrm{nM}$ naltrexone, $10 \mathrm{nM}$ temsirolimus, $100 \mathrm{nM}$ morphine $+10 \mathrm{nM}$ temsirolimus, $10 \mathrm{nM}$ MNTX + $10 \mathrm{nM}$ temsirolimus, $100 \mathrm{nM}$ MNTX $+10 \mathrm{nM}$ temsirolimus or $10 \mathrm{nM}$ naloxone $+10 \mathrm{nM}$ temsirolimus. Experiments were performed in triplicate. Error bars $=$ standard deviation. 


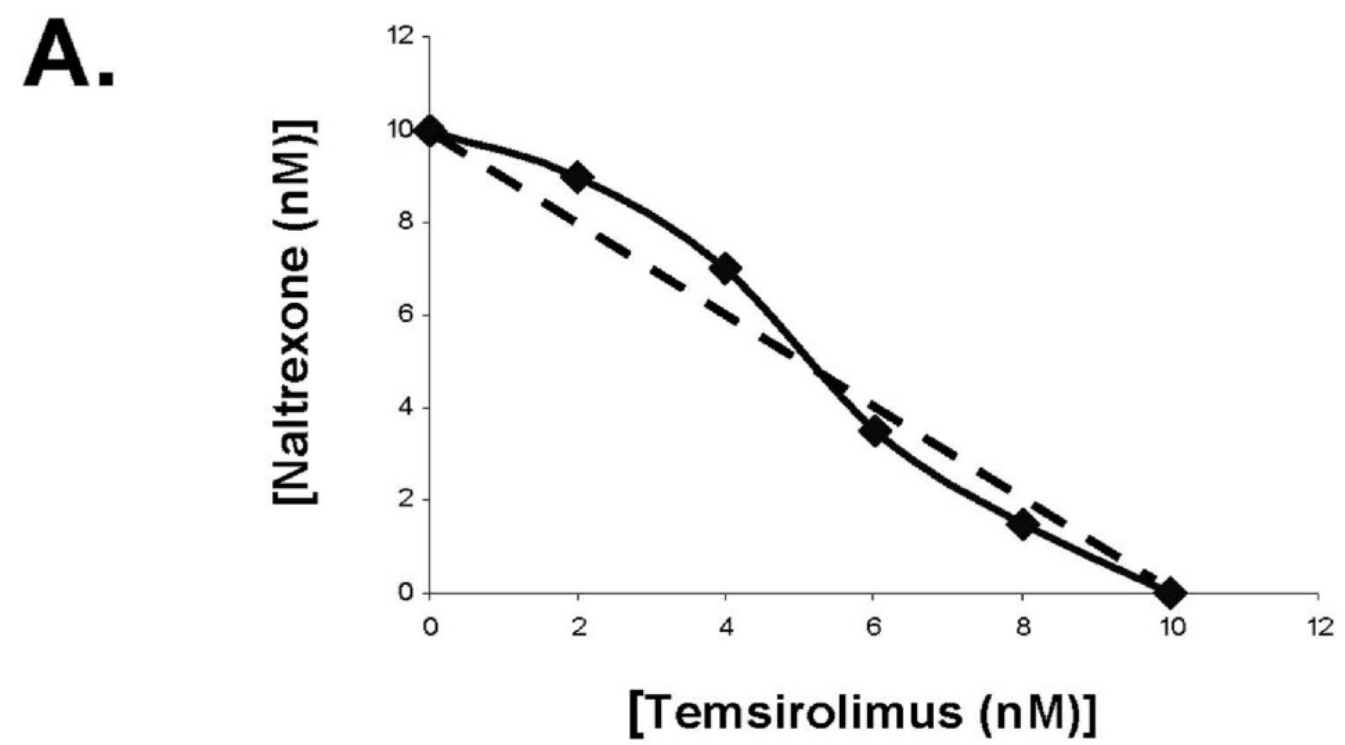

B.

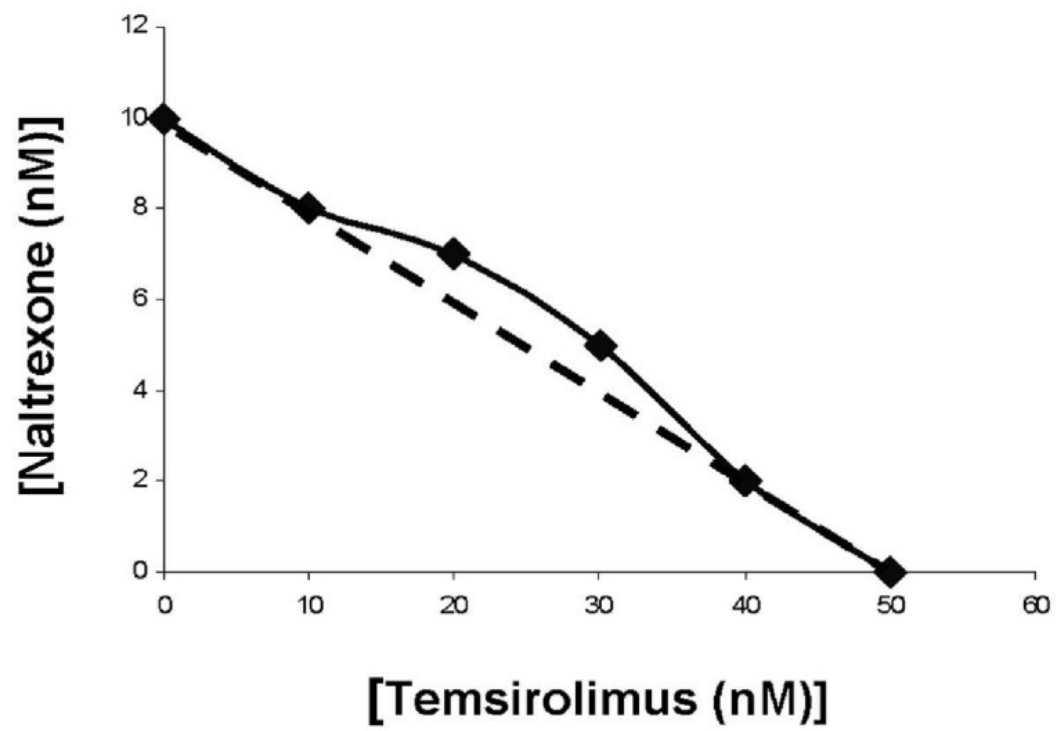

Isobologram analysis indicating a lack of synergy of naltrexone with temsirolimus on VEGF-induced human EC proliferation and migration. Panel A: Isobologram analysis of the combination of naltrexone and temsirolimus on inhibition of VEGF-induced proliferation. The dashed line indicates a zero interaction for the isobole. The close proximity of the data with the dashed line indicates there is not a synergistic interaction. Panel B: Isobologram analysis of the combination of naltrexone and temsirolimus on inhibition of VEGF-induced migration. The dashed line indicates a zero interaction for the isobole. The close proximity of the data with the dashed line indicates there is not a synergistic interaction.

The roles of mTOR Complex components, Akt and Src in MNTX and temsirolimus inhibition of VEGF-induced angiogenesis

We next examined the mechanism(s) of the synergistic effects of MNTX with temsirolimus on inhibition of VEGF-induced angiogenic events. Our previous published data indicate that Akt activation is important in VEGF-induced angiogenesis [ 10]. Akt is activated by threonine phosphorylation $\left(\mathrm{T}^{308}\right)$ in the catalytic domain by PI3 kinase-dependent PDK-1 and by serine phosphorylation $\left(\mathrm{S}^{473}\right)$ in the hydrophobic motif by various kinases including mTOR [ 13- 15]. The substrate specificity of mTOR is regulated by complex formation with other proteins. Specifically, mTOR exists in a rapamycinsensitive complex (mTOR Complex 1) with the regulatory-associated protein of mTOR (Raptor) and a rapamycin-insensitive complex (mTOR Complex 2) with the rapamycin-insensitive companion of mTOR, Rictor [ 1- 5, 13, 15]. We silenced (siRNA) selective proteins in human EC including mTOR (Figure 4-A). Pre-treating human EC with MNTX, temsirolimus or mTOR siRNA followed by VEGF challenge revealed that Akt activation (serine/threonine phosphorylation) is blocked by 
MNTX. Further, silencing mTOR blocked VEGF-induced serine, but not threonine Akt phosphorylation. Interestingly, the mTOR inhibitor, temsirolimus, did not attenuate Akt activation but inhibited the mTOR Complex 1 target p70 S6K [ 4] (Figure 4-B ).

\section{Figure 4}

A.

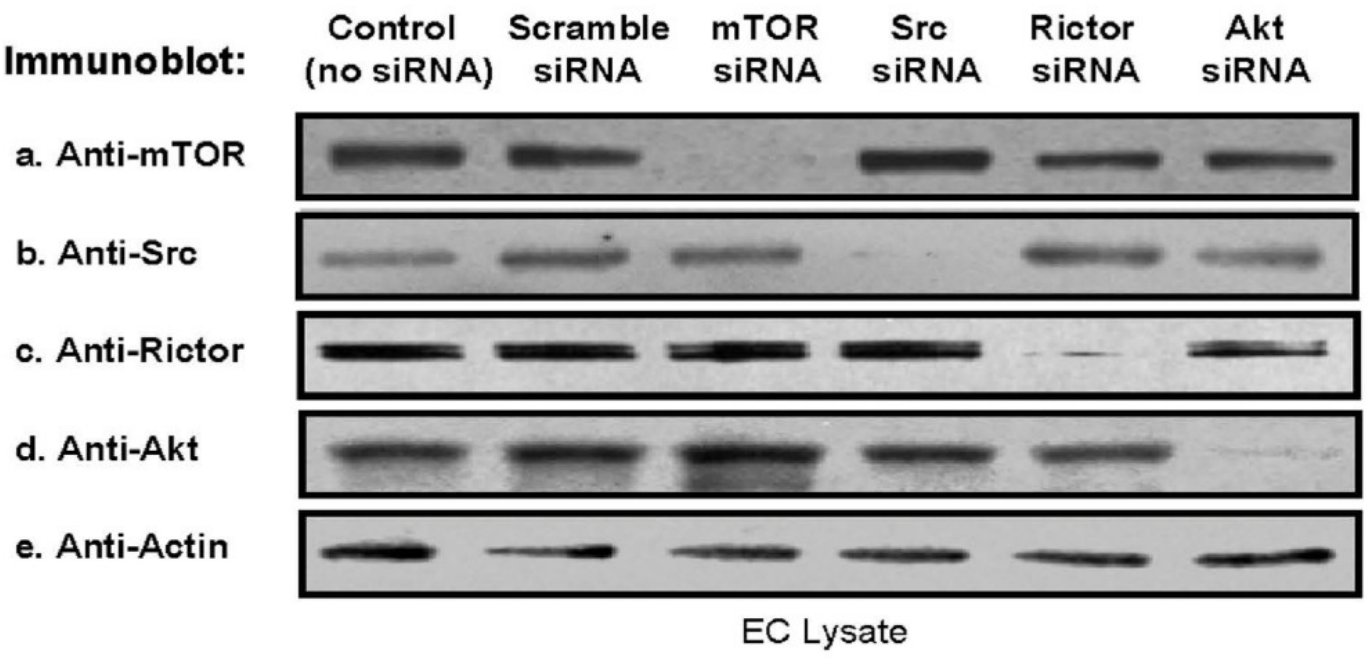

B.

Immunoblot:

a. pSer ${ }^{473} \mathrm{Akt}$

b. $\mathrm{pThr}{ }^{308} \mathrm{Akt}$

c. Akt

d. $\mathrm{pThr}^{389} \mathrm{p} 70$ S6K

e. $\mathrm{p} 70 \mathrm{~S} 6 \mathrm{~K}$ 
temsirolimus pre-treatment indicated that VEGF induces mTOR Complex 1 and mTOR Complex 2 formation. Both MNTX and temsirolimus block mTOR Complex 1 formation while only MNTX blocks mTOR Complex 2 formation (Figure 5-A).

Figure 5

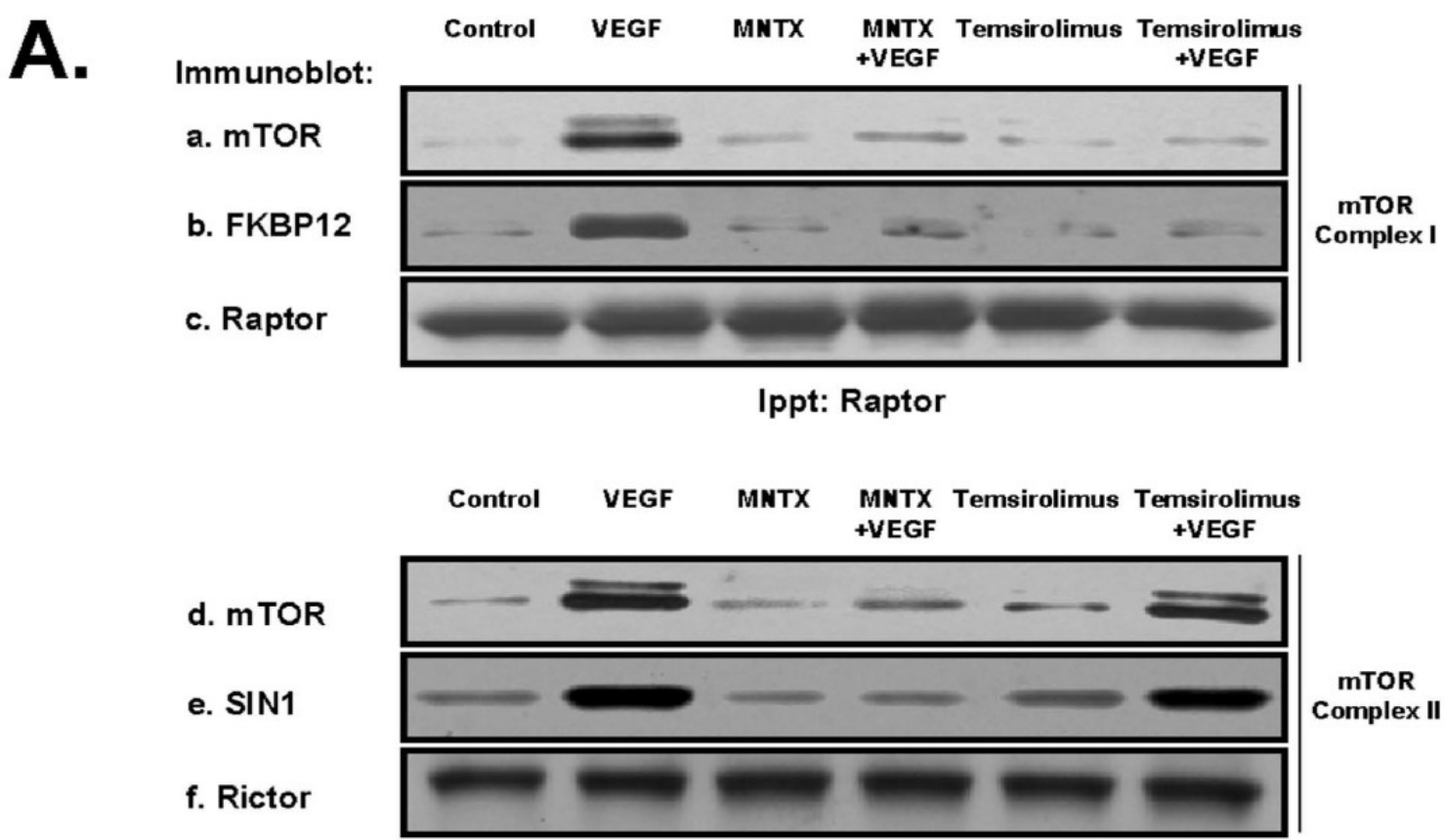

Ippt: Rictor

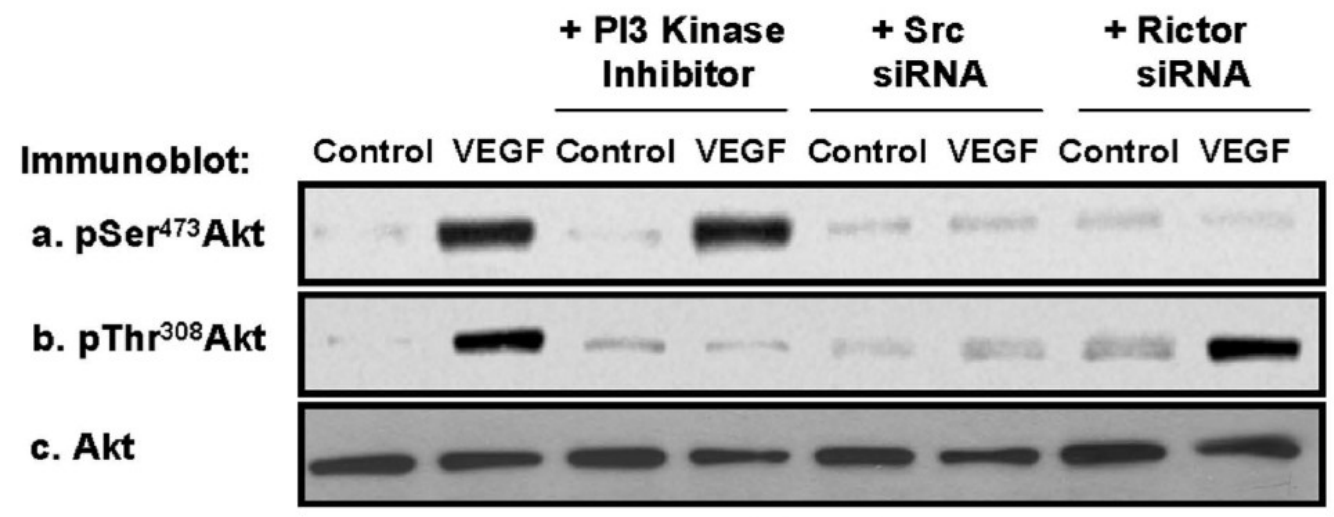

EC Lysate

Determination of mTOR Complex 1 and mTOR Complex 2 regulation of VEGF-induced Akt activation in human EC.

Panel A: Human EC were serum starved for one hour and either untreated (control) or treated with VEGF (100 nM, 5 minutes) with or without pretreatment (1 hour) with $100 \mathrm{nM}$ MNTX or $100 \mathrm{nM}$ temsirolimus. EC were then solublized in IP buffer (50 mM HEPES (pH 7.5), $150 \mathrm{mM} \mathrm{NaCl}, 20 \mathrm{mM} \mathrm{MgCl}_{2}, 1 \%$ Nonidet P-40 (NP-40), $0.2 \mathrm{mM}$ phenylmethylsulfonyl fluoride, 1:250 dilution of Calbiochem protease inhibitor mixture 3) and immunoprecipitated with either anti-Raptor (mTOR Complex 1 component) or anti-Rictor (mTOR Complex 2 component) antibody. The immunoprecipitated material was run on SDS-PAGE and immunoblotted with anti-mTOR (a, d), anti-FKBP12 (mTOR Complex 1 component and direct target of temsirolimus) (b), anti-Raptor (c), anti-SIN1 (mTOR Complex 2 component) (e) or anti-Rictor (f) antibody. Panel B: Human EC were serum starved for one hour and either untreated (control) or treated with VEGF (100 nM, 5 minutes) with or without pretreatment (1 hour) with LY294002 (PI3 kinase inhibitor, 10 $\mu \mathrm{M}$ ) or pretreated for 48 hours with Src or Rictor (mTOR Complex 2 component) siRNA. EC lysates were obtained, run on SDS-PAGE and immunoblotted with anti-pSer ${ }^{473}$ Akt (a), anti-pThr ${ }^{308}$ Akt (b), or anti-AKT (c) antibody.

We and others have previously published that VEGF induces Src and PI3 kinase activation in human EC [ 6, 16, 17]. We inhibited PI3 kinase activity with LY294002 or silenced (siRNA) Src or Rictor (required for mTOR Complex 2 formation), challenged EC with VEGF and examined Akt activation. Our results (Figure 5-B) indicate that Src is required for both serine 
and threonine phosphorylation of Akt, the PI3 kinase pathway is required for threonine phosphorylation of Akt and mTOR Complex 2 is required for serine phosphorylation of Akt.

Similar to our results in Figures 4 and 5 , we observed that silencing (siRNA) of mTOR, Akt, Src, Rictor or inhibition of PI3 kinase activity significantly attenuated VEGF-induced human EC proliferation (Figure 6-A) and migration (Figure 6-B) with Src silencing inducing the greatest inhibition of these activites. In addition, silencing Src or FKBP12 (direct target of temsirolimus $[2,3,5]$ ) blocked the synergy observed with MNTX and temsirolimus on VEGF-induced EC proliferation (Figure 6-C) and migration (Figure 6-D). However, our synergism analysis is complicated by the potent effects of Src and FKBP12 silencing alone.

Figure 6
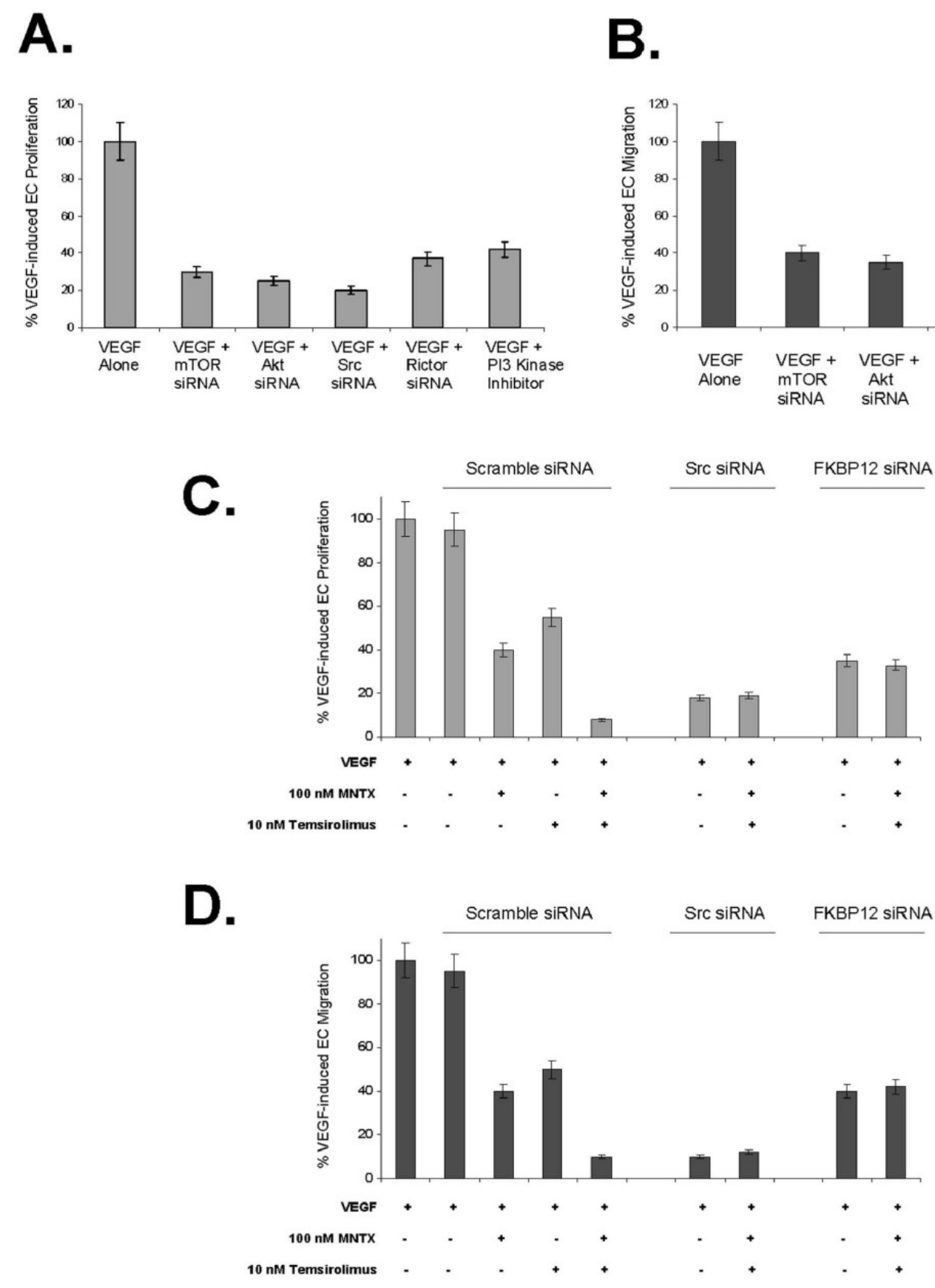

The effects of mTOR, Akt, Src, Rictor and PI3 kinase on VEGF-induced human EC proliferation and migration. Panel A: Bar graph representation of human EC assayed for VEGF (100 nM)-induced proliferation (24 hours) in the presence or absence of 48 hour pretreatment with mTOR siRNA, Akt siRNA, Src siRNA, Rictor (mTOR Complex 2 component) siRNA or pretreatment (1 hour) with LY294002 (PI3 kinase inhibitor, $10 \mu \mathrm{M}$ ). Experiments were performed in triplicate. Error bars = standard deviation. Panel B: Bar graph representation of human EC assayed for VEGF (100 nM)-induced migration (24 hours) in the presence or absence of 48 hour pretreatment with mTOR siRNA, Akt siRNA, Src siRNA, Rictor (mTOR Complex 2 component) siRNA or pretreatment (1 hour) with LY294002 (PI3 kinase inhibitor, $10 \mu \mathrm{M}$ ). Experiments were performed in triplicate. Error bars = standard deviation. Panel C: Bar graph representation of human EC assayed for VEGF (100 nM)-induced proliferation (24 hours) in the presence or absence of 48 hour pretreatment with Src or FKBP12 siRNA with addition of $100 \mathrm{nM}$ MNTX and/or $10 \mathrm{nM}$ temsirolimus. Experiments were performed in triplicate. Error bars = standard deviation. Panel D: Bar graph representation of human EC assayed for VEGF (100 nM)- 


\section{The role of tyrosine phosphatase activity in MNTX and temsirolimus inhibition of VEGF-mediated} angiogenesis

Our previous studies indicate that MNTX attenuates VEGF-induced pp60 Src activation (tyrosine phosphorylation) [ 6, 10]. One possible mechanism of attenuating Src tyrosine phosphorylation is through tyrosine phosphatase activity [ 18, 19]. To investigate this, we measured EC plasma membrane-associated tyrosine phosphatase activity and discovered that VEGF and morphine inhibit, while MNTX promotes tyrosine phosphatase activity (Figure 7-A). Treated of human EC with the potent tyrosine phosphatase inhibitor, 3.4-dephostatin [ 20] blocked MNTX inhibition of VEGF-induced Src and Akt activation (Figure 7-B) and reversed MNTX synergistic effects with temsirolimus on VEGF-induced proliferation (shift in the IC50 from $\sim 1 \mathrm{nM}$ to $\sim 20 \mathrm{nM}$, Figure 7-C) and VEGF-induced migration (shift in the IC50 from $\sim 5 \mathrm{nM}$ to $\sim 70 \mathrm{nM}$, Figure 7-D).

\section{Figure 7}
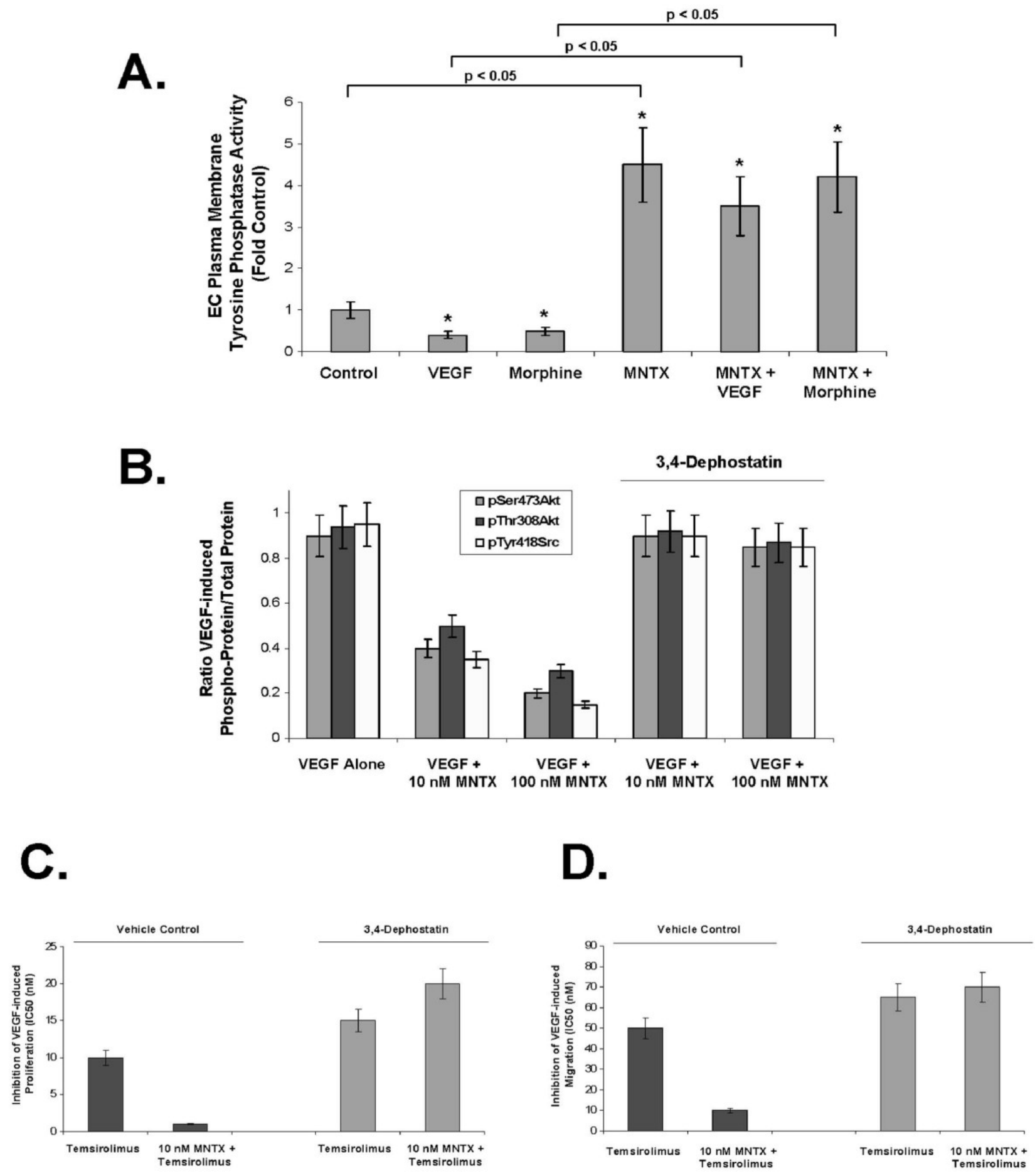
associated tyrosine phosphatase activity (see Methods) with VEGF (100 nM), morphine (100 nM), MNTX (100 nM) or combination treatment. The asterisks indicate a statistically significant difference $(\mathrm{p}<0.05)$ between control and drug challenge. In addition, there is a statistically significant difference ( $p, 0.05)$ between without MNTX and with MNTX treatment. Panel B: Bar graph representation of the ration of phospho-protein to total protein using immunoblot analyses of $\mathrm{pSer}^{473} \mathrm{Akt}, \mathrm{pThr}^{308}$ Akt and $\mathrm{pTyr}^{418} \mathrm{Src}$ of human EC treated with $100 \mathrm{nM}$ VEGF with or without $10 \mathrm{nM}$ or $100 \mathrm{nM}$ MNTX in the presence or absence of the tyrosine phosphatase inhibitor, 3,4-dephostatin $(50 \mu \mathrm{M})$. Experiments were performed in triplicate. Error bars = standard deviation. Panel C: Graphical representation of the 50\% inhibition concentration (IC50, $(\mathrm{nM})$ ) of human EC assayed for VEGF (100 nM)-induced proliferation (24 hours) of temsirolimus with or without $10 \mathrm{nM}$ MNTX in the presence or absence of the tyrosine phosphatase inhibitor, 3,4-dephostatin $(50 \mu \mathrm{M})$. Experiments were performed in triplicate. Error bars = standard deviation. Panel D: Graphical representation of the 50\% inhibition concentration (IC50, (nM)) of human EC assayed for VEGF (100 nM)-induced migration (24 hours) of temsirolimus with or without $10 \mathrm{nM}$ MNTX in the presence or absence of the tyrosine phosphatase inhibitor, 3,4dephostatin $(50 \mu \mathrm{M})$. Experiments were performed in triplicate. Error bars = standard deviation.

\section{In vivo analysis of MNTX synergy with temsirolimus on inhibition of angiogenesis}

Considering the results of our in vitro human EC studies, we next examined the role of MNTX and temsirolimus on angiogenesis in vivo. In the mouse Matrigel plug assay [ 11], addition of $100 \mathrm{nM}$ MNTX inhibited angiogenesis (Figure 8 ). Importantly, addition of MNTX in combination with temsirolimus inhibited angiogenesis to a greater extent than either drug alone (Figure 8). These results indicate MNTX and temsirolimus have a synergistic effect on inhibition of angiogenesis in vivo.

Figure 8 
A.

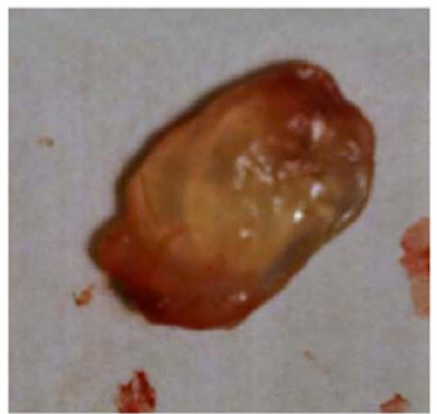

Control

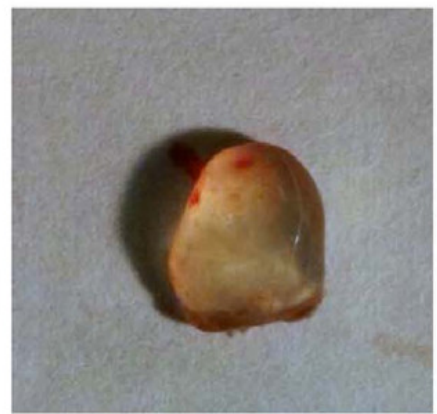

MNTX

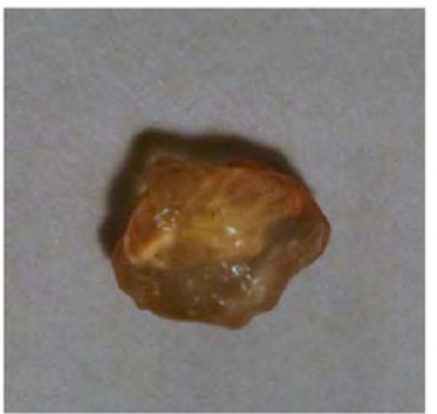

Temsirolimus

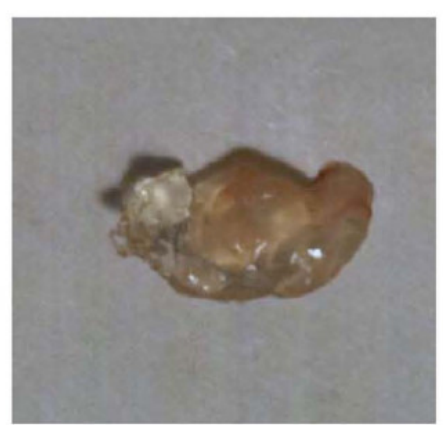

Temsirolimus + MNTX

B.

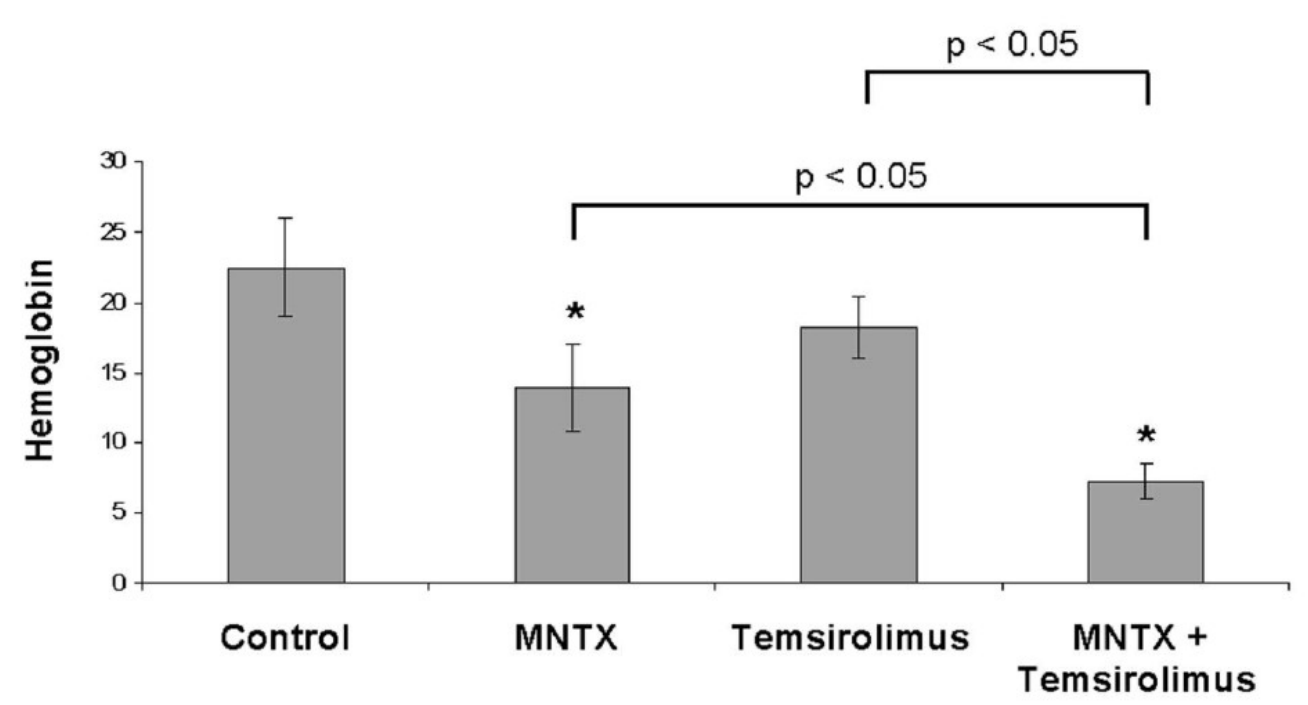

In vivo analysis of MNTX synergy with temsirolimus on inhibition of angiogenesis. In Panels A and B, 10-week-old female C57BL/6 mice (Jackson Laboratory, Bar Harbor, ME) were injected subcutaneously on the ventral abdomen with $500 \mu \mathrm{l}$ Matrigel (BD Biosciences, San Jose, CA) containing either MNTX (100 nM), temsirolimus (10 nM), or both drugs (100 nM MNTX and $10 \mathrm{nM}$ temsirolimus). $20 \mathrm{ng}$ VEGF was added to all Matrigel plugs. After 21 days, the plugs were removed. Panel A: Pictures of Matrigel plugs after removal from mice. Panel B: Graphical analysis of Matrigel plug hemoglobin content. The plugs were weighed and homogenized, and their hemoglobin content was quantified using the QuantiChrom $^{\mathrm{TM}}$ hemoglobin assay kit (BioAssay Systems, Hayward, CA), $\mathrm{n}=3$ per group. The asterisks indicate a statistically significant difference $(\mathrm{p}<0.05)$ between treatment and control. There is also a statistically significant difference $(\mathrm{p}<0.05)$ between MNTX or temsirolimus treatment alone versus in combination.

\section{Discussion}

We and others have previously noted an effect of opiates on endothelial cell migration and proliferation, and an effect of opiate antagonists in attenuating opiate induced angiogenesis $[6,8,10]$. The selective peripheral antagonist of the mu opioid receptor, MNTX, administered subcutaneously, is approved in the USA, EU, Canada and Australia. In the USA, it is 
indicated for the treatment of opioid-induced constipation in patients with advanced illness (i.e. cancer, AIDS) who are receiving palliative care, when responses to laxatives have not been sufficient [ 21-24]. Use in attenuating other side effects of opiates has been studied [ 25]. In this study, we present the novel findings that MNTX acts in a synergistic manner with the mTOR inhibitors, rapamycin and temsirolimus, in inhibiting VEGF-induced angiogenic events. Our results indicate that the synergistic effects of MNTX with mTOR inhibitors are achieved through inhibition of different components of a common VEGF-induced angiogenic signaling pathway. MNTX inhibits the mu opioid receptor and stimulates tyrosine phosphatase activity which inhibits VEGF-induced Src activation and Src-regulated PI3 kinase and mTOR Complex 2-mediated Akt activation. Temsirolimus and rapamycin inhibit the downstream target of activated Akt, mTOR Complex 1 [ 1, 15, 26]. Inhibition of these events promotes synergistic inhibition of VEGF-induced angiogenesis (Figure 9). Therefore, we hypothesize that, in addition to its effects on GI motility, MNTX might have clinical utility by potentially lowering the therapeutic doses of mTOR inhibitors in the treatment of various diseases requiring angiogenesis including cancer. Figure 9

Schematic diagram of a proposed mechanism of MNTX synergistic effects with temsirolimus on inhibition of VEGF-induced angiogenic events. VEGF binding to VEGF receptors (1) induces Src activation (tyrosine phosphorylation)(2), Src-mediated PI3 kinase/PDK1 activation with consequent phospho-threonine ${ }^{308}$ Akt phosphorylation (3) and mTOR Complex 2 formation (mTOR/SIN1/Rictor) with consequent phospho-serine ${ }^{473}$ Akt phosphorylation (4). Activated (serine/threonine phosphorylated) Akt promotes mTOR Complex 1 formation (mTOR/FKBP12/Raptor) (5) required for EC proliferation and migration (6). MNTX inhibits the mu opioid receptor and promotes tyrosine phosphatase activity and Src inactivation (7). Temsirolimus binds to FKBP12 and inhibits mTOR Complex 2 formation (8). Therefore, the synergistic effects of MNTX with temsirolimus are achieved through inhibition of different components of a common VEGF-induced angiogenic signaling pathway. MNTX can have important clinical utility by potentially lower the therapeutic dose of temsirolimus in the treatment of various diseases requiring angiogenesis including cancer.

We have focused our studies on methylnaltrexone (MNTX) because it is more likely to be used in advanced illness clinical settings than tertiary mu opioid receptor antagonists. Uncharged mu opioid antagonists, including naloxone and naltrexone, are fairly lipid soluble and cross the blood-brain barrier easily [ 27-29]. Despite numerous attempts at regulating doses, mu opioid antagonists have proven unsuitable for patients receiving opiates for pain management because of analgesia reversal and breakthrough pain [30]. MNTX is a quaternary derivative of the tertiary mu opiate antagonist naltrexone [ 31]. The addition of the methyl group to naltrexone at the amine in the ring forms the compound $\mathrm{N}$-methylnaltrexone with greater polarity and lower lipid solubility. Because MNTX does not cross the blood-brain barrier, it could play a therapeutic role in reversing the peripheral effects of opiates in palliative care, especially for patients taking high doses of opiates for analgesia [ 32-37]. The plasma concentrations of morphine and MNTX in patients after parenteral or oral administration are consistent with the levels that regulated synergistic inhibition of VEGF-induced angiogenesis and inhibited Src in our in vitro model $(\mathrm{IC} 50=\sim 10 \mathrm{nM})[10]$.

We focused our studies on temsirolimus and rapamycin based on our previous published data that MNTX regulates VEGFinduced Akt activation [ 10] and the intricate relationship between Akt and mTOR pathways [ 5, 26]. Both rapamycin and temsirolimus, a soluble ester analog of rapamycin, exert their action by binding to the intracellular protein, FKBP12, and inhibiting mTOR Complex 1 formation [ 38-40]. However, mTOR can still complex with SIN1 and Rictor (mTOR Complex 2) $[1,15,26]$. The mTOR Complex 2 serine phosphorylates Akt and is involved in actin cytoskeletal regulation [ 2, 4, 14, 41, 42]. Akt can also be threonine phosphorylated by PI3 kinase activation of PDK1 [ 41- 45]. Activated (serine/threonine phosphorylated) Akt promotes mTOR Complex 1 assembly through inactivation (phosphorylation) of TSC2 and PRAS40 [ 5, 26]. Activated mTOR Complex 1 phosphorylates several target proteins including S6K and 4EBP1 involved in cell proliferation, growth and survival $[1,2,4,5,26]$.

The effects of MNTX on inhibition of mTOR described in this manuscript go beyond VEGF receptor activation and extend to downstream signaling pathways. We and others have previously reported that inhibition of Src protects from EC barrier disruption and angiogenesis [ 6, 8, 10]. Src regulates several potential angiogenic events including EC contraction and vascular permeability [ 43,44$]$. We extended these finding by observing that Src regulates VEGF-induced, PI3 kinase and mTOR-dependent, serine/threonine phosphorylation of Akt important for EC proliferation and migration. Further, Src regulates the synergistic effects of MNTX with temsirolimus on inhibition of VEGF-induced angiogenic events. We have previously demonstrated that MNTX increases tyrosine phosphatase activity, including RPTP $\mu$ [ 10]. This study extends these finding by demonstrating that the potent protein tyrosine phosphatase inhibitor, 3,4-Dephostatin, blocks MNTX inhibition of VEGF-induced Src and Akt phosphorylation. 3,4-Dephostatin is known to block the phosphatase activity of PTP-1B, SHPTP-1 and CD45 [ 20, 40, 46- 48]. In addition, 3,4-Dephostatin increased insulin-induced tyrosine phosphorylation of PLC $\gamma, \mathrm{c}-\mathrm{Cbl}$ and the regulatory subunit of PI3 kinase (a known Src substrate) [ 48]. We are currently examining the role of these tyrosine phosphatases in MNTX inhibition of VEGF-induced Src activation and angiogenesis.

Temsirolimus was approved by the FDA in 2007 for the treatment of advanced renal cell carcinoma, a disease resistant to existing chemotherapies (IFN- $\alpha$, IL-2) [ 3, 38-40]. There have been other attempts to potentiate the action of temsirolimus. In Phase 3 clinical trails, temsirolimus, IFN- $\alpha$ or temsirolimus + IFN- $\alpha$ treatment resulted in median survival rates of 10.9 months, 7.3 months and 8.4 months, respectively [ 3,38-40]. IFN- $\alpha$ did not augment temsirolimus treatment alone [ $3,38-$ 40]. The results of these clinical trials indicate the need for an effective drug in temsirolimus combination therapy. Our observations that MNTX acts synergistically with mTOR inhibitors on inhibition of VEGF-induced angiogenic events merit clinical studies.

\section{Conclusions}

Our results indicate that MNTX exerts a synergistic effect with rapamycin and temsirolimus on inhibition of VEGF-induced human EC proliferation and migration and in vivo angiogenesis. These synergistic effects are achieved through inhibition of different components of a common VEGF-induced angiogenic signaling pathway. MNTX inhibits the mu opioid receptor and 
stimulates tyrosine phosphatase activity which inhibits VEGF-induced Src activation and Src-regulated PI3 kinase and mTOR Complex 2-mediated Akt activation. Temsirolimus and rapamycin inhibit the downstream target of activated Akt, mTOR Complex 1. Inhibition of these events promotes synergistic inhibition of VEGF-induced angiogenesis (Figure 9). Therefore, addition of MNTX could potentially lower the dose of mTOR inhibitors which could improve therapeutic index.

Additional file 1: Determination of methylnaltrexone (MNTX) synergistic effects with rapamycin on inhibition of VEGF-induced human endothelial cell (EC) proliferation and migration. This file shows through inhibition curves and isobologram analysis that MNTX acts synergistically with the mTOR inhibitor, rapamycin, on inhibition of VEGF-induced angiogenic events. (PDF $20 \mathrm{~KB}$ )

\section{Declarations}

\section{Authors' original submitted files for images}

Below are the links to the authors' original submitted files for images.

Authors' original file for figure 1

Authors' original file for figure 2

Authors' original file for figure 3

Authors' original file for figure 4

Authors' original file for figure 5

Authors' original file for figure 6

Authors' original file for figure 7

Authors' original file for figure 8

Authors' original file for figure 9

\section{Competing interests}

Dr. Moss serves as a paid consultant to Progenics Pharmaceuticals, Inc., has a financial interest in methylnaltrexone as a patent holder through the University of Chicago, and receives stock options from Progenics. Drs. Singleton and Garcia are co-inventors on patents with Dr. Moss. The other authors declare they have no competing interests.

\section{Authors' contributions}

PAS helped conceive of the study, and participated in its design and coordination, performed the in vitro inhibition and isobologram assays and helped draft the manuscript. NM participated in the study design and conducted immunoprecipitation and immunoblot assays. FEL, BM and JHS participated in the study design and performed the in vivo Matrigel plug assays. LMV coordinated the animal studies by FEL, BM and JHS. RS participated in the design and coordination of the studies. JM helped conceive of the study, and participated in its design and coordination, and helped draft the manuscript. JGNG coordinated the work of LMV, BM and JHS. All authors read and approve the final manuscript.

\section{References}

1. Brachmann S, Fritsch C, Maira SM, Garcia-Echeverria C. PI3K and mTOR inhibitors: a new generation of targeted anticancer agents. Curr Opin Cell Biol. 2009;21:194-8.

$\underline{\text { View Article }} \underline{\text { Google Scholar }}$

2. Fasolo A, Sessa C. mTOR inhibitors in the treatment of cancer. Expert Opin Investig Drugs. 2008;17:1717-34. View Article Google Scholar

3. Malizzia LJ, Hsu A. Temsirolimus, an mTOR inhibitor for treatment of patients with advanced renal cell carcinoma. Clin J Oncol Nurs. 2008;12:639-46.

View Article $\underline{\text { Google Scholar }}$

4. Abraham RT, Gibbons JJ. The mammalian target of rapamycin signaling pathway: twists and turns in the road to cancer therapy. Clin Cancer Res. 2007;13:3109-14.

View Article Google Scholar

5. Faivre S, Kroemer G, Raymond E. Current development of mTOR inhibitors as anticancer agents. Nat Rev Drug Discov. 2006;5:671-88.

View Article $\underline{\text { Google Scholar }}$ 
6. Singleton PA, Lingen MW, Fekete MJ, Garcia JG, Moss J. Methylnaltrexone inhibits opiate and VEGF-induced angiogenesis: Role of receptor transactivation. Microvasc Res. 2006;72:3-11.

View Article Google Scholar

7. Singleton PA, Dudek SM, Ma SF, Garcia JGN. Transactivation of sphingosine 1-phosphate receptors is essential for vascular barrier regulation. Novel role for hyaluronan and CD44 receptor family. J Biol Chem. 2006;281:34381-93.

View Article $\underline{\text { Google Scholar }}$

8. Singleton PA, Moreno-Vinasco L, Sammani S, Wanderling SL, Moss J, Garcia JGN. Attenuation of Vascular Permeability by Methylnaltrexone: Role of mOP-R and S1P3 Transactivation. Am J Respir Cell Mol Biol. 2007;37:222-31.

View Article $\underline{\text { Google Scholar }}$

9. Wang Y Ao X Vuong H Konanur M Miller FR Goodison S Lubman DM Membrane Glycoproteins Associated with Breast Tumor Cell Progression Identified by a Lectin Affinity Approach J Proteome Res 20087431343252630886 10.1021/pr8002547

10. Singleton PA, Garcia JGN, Moss J. Synergistic effects of methylnaltrexone with 5-fluorouracil and bevacizumab on inhibition of vascular endothelial growth factor-induced angiogenesis. Mol Cancer Ther. 2008;7:1669-79.

View Article Google Scholar

11. Liu Z, Kobayashi K, van Dinther M, van Heiningen SH, Valdimarsdottir G, van Laar T, Scharpfenecker M, Lowik CW, Goumans MJ, Ten Dijke P, Pardali E. VEGF and inhibitors of TGFbeta type-I receptor kinase synergistically promote blood-vessel formation by inducing alpha5-integrin expression. J Cell Sci. 2009;122:3294-302. View Article Google Scholar

12. Tallarida RJ. Drug synergism: its detection and applications. J Pharmacol Exp Ther. 2001;298:865-72. View Article $\underline{\text { Google Scholar }}$

13. Hutson TE. Targeted therapy for renal cell carcinoma: a new treatment paradigm. Proc (Bayl Univ Med Cent). 2007;20:244-8

View Article Google Scholar

14. Jacinto E, Loewith R, Schmidt A, Lin S, Ruegg MA, Hall A, Hall MN. Mammalian TOR complex 2 controls the actin cytoskeleton and is rapamycin insensitive. Nat Cell Biol. 2004;6:1122-8.

View Article Google Scholar

15. Sarbassov DD, Ali SM, Kim DH, Guertin DA, Latek RR, Erdjument-Bromage H, Tempst P, Sabatini DM. Rictor, a novel binding partner of mTOR, defines a rapamycin-insensitive and raptor-independent pathway that regulates the cytoskeleton. Curr Biol. 2004;14:1296-302.

View Article Google Scholar

16. Duval M Le Boeuf F Huot J Gratton JP Src-mediated phosphorylation of Hsp90 in response to vascular endothelial growth factor (VEGF) is required for VEGF receptor-2 signaling to endothelial NO synthase Mol Biol Cell 2007184659682043550 10.1091/mbc.E07-05-0467

17. Dawson NS, Zawieja DC, Wu MH, Granger HJ. Signaling pathways mediating VEGF165-induced calcium transients and membrane depolarization in human endothelial cells. Faseb J. 2006;20:991-3.

View Article Google Scholar

18. den Hertog J, Groen A, Wijk T van der. Redox regulation of protein-tyrosine phosphatases. Arch Biochem Biophys. 2005;434:11-5.

View Article $\underline{\text { Google Scholar }}$

19. Stoker AW. Protein tyrosine phosphatases and signalling. J Endocrinol. 2005;185:19-33.

View Article Google Scholar

20. Umezawa K, Kawakami M, Watanabe T. Molecular design and biological activities of protein-tyrosine phosphatase inhibitors. Pharmacol Ther. 2003;99:15-24.

View Article Google Scholar

21. Slatkin N, Thomas J, Lipman AG, Wilson G, Boatwright ML, Wellman C, Zhukovsky DS, Stephenson R, Portenoy R, Stambler N, Israel R. Methylnaltrexone for treatment of opioid-induced constipation in advanced illness patients. J Support Oncol. 2009;7:39-46. 
22. Thomas J, Karver S, Cooney GA, Chamberlain BH, Watt CK, Slatkin NE, Stambler N, Kremer AB, Israel RJ. Methylnaltrexone for opioid-induced constipation in advanced illness. N Engl J Med. 2008;358:2332-43. View Article Google Scholar

23. Portenoy RK, Thomas J, Moehl Boatwright ML, Tran D, Galasso FL, Stambler N, Von Gunten CF, Israel RJ. Subcutaneous methylnaltrexone for the treatment of opioid-induced constipation in patients with advanced illness: a double-blind, randomized, parallel group, dose-ranging study. J Pain Symptom Manage. 2008;35:45868.

$\underline{\text { View Article } \text { Google Scholar }}$

24. Methylnaltrexone (Relistor) for opioid induced constipation. Med Lett Drugs Ther. 2008, 50: 63-4.

25. Moss J, Rosow CE. Development of peripheral opioid antagonists' new insights into opioid effects. Mayo Clin Proc. 2008;83:1116-30

View Article Google Scholar

26. Garcia JA Danielpour D Mammalian target of rapamycin inhibition as a therapeutic strategy in the management of urologic malignancies Mol Cancer Ther 200871347 542587303 10.1158/1535-7163.MCT07-2408

27. Moss J, Foss J. . Pain Relief without Side Effects: Peripheral Opiate Antagonists. 2005;:- . View Article Google Scholar

28. Hoskin PJ, Hanks GW. Opioid agonist-antagonist drugs in acute and chronic pain states. Drugs. 1991;41:326-44. View Article Google Scholar

29. Greenwood-Van Meerveld B, Gardner CJ, Little PJ, Hicks GA, Dehaven-Hudkins DL. Preclinical studies of opioids and opioid antagonists on gastrointestinal function. Neurogastroenterol Motil. 2004;16:46-53.

View Article Google Scholar

30. Sykes NP. . Using Oral Naloxone in Management of Opioid Bowel Dysfunction. 2005;:-

View Article Google Scholar

31. Yuan CS, Foss JF, O'Connor M, Osinski J, Karrison T, Moss J, Roizen MF. Methylnaltrexone for reversal of constipation due to chronic methadone use: a randomized controlled trial. Jama. 2000;283:367-72.

View Article Google Scholar

32. Stanski DR, Greenblatt DJ, Lowenstein E. Kinetics of intravenous and intramuscular morphine. Clin Pharmacol Ther. 1978;24:52-9.

View Article Google Scholar

33. Neumann PB, Henriksen H, Grosman N, Christensen CB. Plasma morphine concentrations during chronic oral administration in patients with cancer pain. Pain. 1982;13:247-52.

View Article Google Scholar

34. Collins SL, Faura CC, Moore RA, McQuay HJ. Peak plasma concentrations after oral morphine: a systematic review. J Pain Symptom Manage. 1998;16:388-402.

View Article Google Scholar

35. Yuan CS, Doshan H, Charney MR, O'Connor M, Karrison T, Maleckar SA, Israel RJ, Moss J. Tolerability, gut effects, and pharmacokinetics of methylnaltrexone following repeated intravenous administration in humans. J Clin Pharmacol. 2005;45:538-46.

View Article Google Scholar

36. Cannom RR, Mason RJ. Methylnaltrexone: the answer to opioid-induced constipation?. Expert Opin Pharmacother. 2009;10:1039-45.

View Article Google Scholar

37. Laustsen G, Carrillo F, Johnson J, Smith C. Drug approvals: '08 in review. Methylnaltrexone (Relistor). Nurse Pract. 2009;34:31-.

View Article Google Scholar

38. Bhatia S, Thompson JA. Temsirolimus in patients with advanced renal cell carcinoma: an overview. Adv Ther. 2009;26:55-67. 
39. Hudes G, Carducci M, Tomczak P, Dutcher J, Figlin R, Kapoor A, Staroslawska E, Sosman J, McDermott D, Bodrogi I, Kovacevic Z, Lesovoy V, Schmidt-Wolf IG, Barbarash O, Gokmen E, O'Toole T, Lustgarten S, Moore L, Motzer RJ. Temsirolimus, interferon alfa, or both for advanced renal-cell carcinoma. N Engl J Med. 2007;356:2271-81. View Article Google Scholar

40. Figlin RA. Mechanisms of Disease: survival benefit of temsirolimus validates a role for mTOR in the management of advanced RCC. Nat Clin Pract Oncol. 2008;5:601-9.

View Article Google Scholar

41. Manning BD Cantley LC AKT/PKB signaling: navigating downstream Cell 20071291261742756685 10.1016/j.cell.2007.06.009

42. Frost RA, Lang CH. Protein kinase B/Akt: a nexus of growth factor and cytokine signaling in determining muscle mass. J Appl Physiol. 2007;103:378-87.

View Article Google Scholar

43. Mucha DR, Myers CL, Schaeffer RC. Endothelial contraction and monolayer hyperpermeability are regulated by Src kinase. Am J Physiol Heart Circ Physiol. 2003;284:H994-H1002.

View Article Google Scholar

44. Weis S Cui J Barnes L Cheresh D Endothelial barrier disruption by VEGF-mediated Src activity potentiates tumor cell extravasation and metastasis J Cell Biol 2004167223 92172541 10.1083/jcb.200408130

45. Chen R, Kim O, Yang J, Sato K, Eisenmann KM, McCarthy J, Chen H, Qiu Y. Regulation of Akt/PKB activation by tyrosine phosphorylation. J Biol Chem. 2001;276:31858-62.

View Article Google Scholar

46. Liu G. Protein tyrosine phosphatase 1B inhibition: opportunities and challenges. Curr Med Chem. 2003;10:1407-21.

View Article Google Scholar

47. Kakeya H, Imoto M, Takahashi Y, Naganawa H, Takeuchi T, Umezawa K. Dephostatin, a novel protein tyrosine phosphatase inhibitor produced by Streptomyces. II. Structure determination. J Antibiot (Tokyo). 1993;46:1716-9.

View Article Google Scholar

48. Suzuki T, Hiroki A, Watanabe T, Yamashita T, Takei I, Umezawa K. Potentiation of insulin-related signal transduction by a novel protein-tyrosine phosphatase inhibitor, Et-3,4-dephostatin, on cultured 3T3-L1 adipocytes. J Biol Chem. 2001;276:27511-8.

View Article Google Scholar 